\title{
LA REVUELTA DE LOS HIJOS DE INMIGRANTES AFRICANOS EN OTOÑO 2005: CRISIS DE LA INTEGRACIÓN REPUBLICANA FRANCESA
}

FRANCIS MESTRIES

\section{INTRODUCCIÓN}

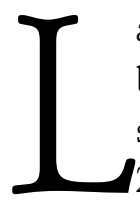

a revuelta callejera de los suburbios de las ciudades francesas en octubre-noviembre de 2005 ha sido calificada como la más grave rebelión popular desde 1968 por los servicios de inteligencia de la policía francesa. Si bien desde 1981 y, sobre todo, 1990 los «rodeos» de quema de coches y choques con la policía eran una tradición de los jóvenes ciertos fines de semana y feriados, con connotaciones «lúdicas» y mediáticas, nunca se habían desatado simultáneamente en tantas ciudades y por tanto tiempo, desbordándose a algunos países limítrofes, ni habían atacado edificios públicos, comercios y escuelas.

La magnitud de la revuelta puso el dedo en la llaga de la creciente incapacidad del modelo francés de integración de absorber social, económica y políticamente a los inmigrantes y a las minorías étnicas francesas hijas de ellos (de 2o. y 3o. generación). Esto remite a la crisis de las principales instituciones: del estado de bienestar, del urbanismo social, de la escuela, de la justicia, de la policía y de la familia en un marco estructural de estancamiento económico y desempleo.

Para explicar esta revuelta, se han manejado interpretaciones falsas e ideológicas: no se trató de motines raciales como los de los guetos de EUA, ni los suburbios populares franceses son guetos, pues no hubo agresiones racistas contra personas, ni se trató de bandas mafiosas que buscaban crear territorios fuera de la ley para sus narcotráficos, como lo insinuó el Ministro del Interior, Nicolás Sarkozy, ni de asonadas insurreccionales del fundamentalismo musulmán, como lo temen los partidos de ultra-derecha. Lo que llama la atención es la falta de proyecto político y de utopía social de esta revuelta anarquizante de carácter 
espontáneo y expresivo contra la marginación económica y la discriminación social.

\section{I) LA REVUELTA}

El movimiento de los jóvenes suburbanos de ascendencia africana inició el 27 de octubre. Como en muchos motines callejeros anteriores en Francia y en Los Angeles en 1992, surgió a raíz de la persecución de la policía a tres jóvenes sospechosos de robo en Clichy-sous-Bois, suburbio de la Seine Saint-Denis al noreste de Paris, los que para evitar abusos policiacos se refugiaron en un transformador eléctrico en donde dos murieron electrocutados. Se desataron entonces quemas de coches y enfrentamientos con la policía en la zona, pero el tiro de gases lacrimógenos contra una mezquita y las declaraciones de Sarkozy de estar decidido a «limpiar la escoria» de los suburbios prendió la mecha en toda la región parisina. En noviembre, la revuelta se extendió a otras ciudades francesas y llegó hasta el centro de Paris; las banlieues de las grandes ciudades de casi toda Francia ardían de noche, de Estrasburgo a Rennes y de Niza a Lille. El 8 de noviembre, la revuelta contagia algunos barrios de Bruselas y de Berlín y Brema: Bélgica y Alemania registran también altas concentraciones de minorías de origen magrebí o turco. La Unión de Organizaciones Islámicas de Francia declaró una fatua contra los incendiarios, aunque otro líder religioso musulmán se declarara en contra. Se registra la pri- mera y última muerte a causa de los motines, un hombre blanco de 65 años en Stains, Seine St. Denis. Los disturbios se extienden a Atenas, Rótterdam y Bruselas, pero en poca escala. El 12 de noviembre, en un intento por controlar el movimiento, el gobierno decreta el toque de queda y el estado de emergencia que prohíbe las reuniones públicas nocturnas, autoriza sanciones penales sumarias y cateos perentorios. Esta medida, amparada en una ley promulgada en 1955 para luchar contra los revolucionarios argelinos, totalmente desproporcionada respecto al carácter de «fiebre juvenil» de estos motines, fue repudiada por las minorías árabe y africana por su sabor colonialista, y muchos alcaldes no la quisieron aplicar. Además, el gobierno detiene a miles de amotinados, expulsa a algunos por ser extranjeros y amenaza cancelar los subsidios a las familias numerosas cuyos padres no hayan podido controlar a sus hijos. La revuelta se va apaciguando, pero el 15 el gobierno decide prolongar por tres meses más el toque de queda, a pesar de la oposición de los partidos de izquierda, aunque al final se levantó en enero.

En suma, luego de tres semanas de revuelta, el balance es de más de 10,000 vehículos y decenas de edificios quemados: escuelas, bibliotecas, gimnasios, comisarías, tribunales, alcaldías, bodegas, comercios, talleres y, en algunos casos, iglesias y sinagogas. Los amotinados concentraron sus ataques contra oficinas del Estado, en menor medida contra empresas y centros comerciales, evitando los templos de cul- 
to. Pero afectaron muchos coches de gente de su misma condición en sus colonias, incluso de inmigrados, en un acceso de rabia parcialmente autodestructora. Practicaron tácticas de guerrilla urbana, usando teléfonos celulares para coordinar a los muchos pequeños grupos de activistas y escapando de la policía luego de aventar sus bombas molotov.

La respuesta del Estado fue de firmeza, movilizando 11,000 policías y hasta helicópteros, que arrestaron a casi 3,000 personas, un tercio de ellos menores de edad, pocos extranjeros y muy pocos con antecedentes penales; de esos 600 serán consignados. Sin embargo, la competencia entre Sarkozy y De Villepin, primer ministro, por la candidatura presidencial en 2007, se tradujo en una política de dos vertientes: de mano dura por parte del primero, y de "comprensión y diálogo» por parte del segundo, aunque la primera fue la dominante (Morice A., 2005).

\section{II) LOS BARRIOS SUBURBANOS DE GRANDES CONJUNTOS HABITACIONALES}

Suburbio se dice banlieue en francés, que viene de bannir, mettre au ban, que quiere decir excluir, desterrar: la banlieue ha sido el lugar, fuera de la capital, en donde se relega a los indeseables del reino. La historia de la instalación de familias inmigradas en esas ciudades periféricas construidas para alojar a la clase obrera después de la 2a. Guerra Mundial inició a fines de los años 50, durante la guerra de Argelia, cuando llegaron muchas familias argelinas huyendo del conflicto; luego otros inmigrantes del Magreb se sumaron a ellas, y últimamente muchas familias del África negra, por ser viviendas de interés social de renta moderada. La población francesa blanca y cristiana se fue reduciendo al mismo tiempo, por lo que la mayoría de la población son franceses de 2a. o $3 \mathrm{a}$. generación de inmigrantes de origen extra-europeo (Boils, 2006). Estos barrios se conforman con grandes conjuntos de torres de 15 a 20 pisos iguales, con escaso tejido comercial, recreativo, cultural y de transporte, sin centros ni plazas atractivas; los edificios están muy deteriorados (fallas de elevador, de agua, de recolección de la basura, de vigilancia, de mantenimiento de áreas comunes) por su proceso de envejecimiento (algunos datan de hace medio siglo), por la desatención de las autoridades municipales, por la falta de pago de muchos inquilinos de escasos recursos y por la autodestrucción de sus habitantes, que no los sienten propios (Ibid.). Son ciudades-dormitorio lejanas de los centros metropolitanos, donde fueron expulsados los pobres de la capital y alojadas las poblaciones alógenas. Estos conjuntos habitacionales albergaban 1'530,000 viviendas, o sea 6\% de los hogares de Francia; se contaban 752 zonas urbanas degradadas, atestadas y riesgosas, por lo que el gobierno optó por demoler o rehabilitar varios conjuntos desde los años 80 , pero el ritmo ha sido lento: en 2001, se tendrían 250,000 viviendas nuevas y 40,000 renovadas (Ibid.). Para colmo, hay un déficit de 1'300,000 viviendas 
(320,000 en la zona metropolitana de Paris, solamente), lo que provoca que en las colonias pobres vivan dos familias en la misma casa y que haya muchos sin hogar. Esto se agrava aun más por el tamaño de las familias de inmigrantes africanos, que suelen ser numerosas (de 3 a 10 hijos) frente al exigüidad de los departamentos $\left(28 \mathrm{~m}^{2}\right.$ promedio para 5 personas).

Aunado a esto impera en estas colonias el desempleo, insuficientemente paliado por las ayudas del gobierno, y los empleos precarios y mal pagados de los jóvenes, aún cuando son franceses y viven por 2 generaciones en Francia. Así, en Aubervilliers, 12.4\% de los hogares viven del RMI, ${ }^{1} 18.3 \%$ reciben la $\mathrm{CMU}^{2}$ las ayudas a familias numerosas se triplicaron en 3 años y el ingreso promedio de los hogares exentos de impuestos es de 465 euros.

Se ha hablado mucho de guetos para comparar estos barrios con los de eUA debido a la omnipresencia de la droga, de las pandillas, de la pequeña delincuencia y de la hostilidad entre éstos y los barrios contiguos de pabellones de clases medias francesas blancas, etc. Sin embargo, no se pueden considerar guetos, ya que no son producto de una política o una práctica social de segregación racial, de apartheid: en los conjuntos habitacionales conviven inmigrantes africanos, europeos, hijos de inmigrantes y franceses blancos (galos); además, como ya se dijo, el Estado está presente y mantiene servicios públicos (educación, sa- lud, vivienda subvencionada, etc.), y, además, la gente vive más de recursos lícitos (salarios, prestaciones sociales), que ilícitos (tráfico de droga, robos) lo que los diferencia de los guetos negros americanos (Rey y Body-Gendrot, 1999). Finalmente, en muchas partes existe una trama asociativa multiétnica que lucha contra las adicciones, los malos servicios y promueve actividades culturales y deportivas.

No obstante, es de notar una tendencia a la conjunción de antagonismos de tipo social, étnico y generacional en esos barrios (Bruneau, 2004) y con las colonias adyacentes, que se acentúan por el vaciamiento de los pobladores "galos» y la «etnicización» de las banlieues.

\section{III) ESTRUCTURA FAMILIAR DE LOS INMIGRANTES AFRICANOS}

El análisis antropológico permite detectar procesos de confrontación, transformación y adaptación de las costumbres y sistemas de valores de las familias de inmigrantes de origen magrebí o sub-sahariano en Francia: la estructura familiar (extensa), las costumbres de endogamia y el estatus de inferioridad de la mujer de las sociedades patrilineales de África del Norte, así como la poligamia, la tradición comunitaria y las altas tasas de fecundidad de las familias de África negra que chocan con las normas familiares, los valores y los tipos de vivienda que im-

\footnotetext{
${ }^{1}$ Ingreso Mínimo de Inserción, subsidio económico módico dado por el gobierno a las personas sin ingresos.

${ }^{2}$ Cobertura Médica Universal. 
peran en Francia (Todd, 1994). Familias ampliadas como las aludidas no son compatibles con los diminutos alojamientos de interés social franceses, ni la sumisión y enclaustramiento de la mujer lo es con el grado de participación casi igualitario de la mujer francesa en la vida pública. «Los inmigrantes vienen de sociedades (africanas) con enormes contrastes con la cultura francesa no fáciles de superar ni por los pobres que emigran, ni por los ricos que los reciben: diferencias en formas de ver el mundo, comportamientos sociales que chocan con los establecidos en la sociedad receptora, niveles de preparación que tienen poco que ver con los requeridos allí. A nivel cultural, el principal problema es la manera diferente de ver la integración de la mujer.» (Castaingts, 2005).

Empero, las estructuras familiares tradicionales sufren profundas mutaciones con la experiencia de la migración: con el tiempo y la inmersión de los hijos en la lengua, la escuela y la cultura de la sociedad receptora es imposible mantener la familia patriarcal, el encierro de la mujer y la endogamia; la fuerte presión cultural de la sociedad sobre las familias de inmigrantes conlleva un choque entre valores individualistas e igualitaristas y valores comunitaristas y patrilineares provocando una implosión de la familia musulmana tradicional (Todd, Ibid.):

lo(a)s adolescentes cuestionan la estructura familiar autoritaria y patriarcal, rechazan la actitud humilde de sus padres en la sociedad dominante y su destino ocupacional, las muchachas rehúsan el matrimonio endogámico y la vida de ama de casa y buscan destacar en sus estudios; la diferencia de nivel educativo entre padres analfabetas e hijos con educación secundaria otorga más prestigio a éstos, lo que socava aun más la autoridad paterna. Como consecuencia, la desintegración familiar amenaza a estas familias, con su efecto más grave, la desorganización de la relación padres-hijos (hay casos de niños que golpean a su madre), y el riesgo constante de caer en la delincuencia para los muchachos. En las familias polígamas o monoparentales dirigidas por mujeres de África negra, cada vez más frecuentes, también existe este riesgo latente por la falta de figura paterna (Quiminal, 1999). Es en esas familias africanas negras recién inmigradas en donde se concentra la mayor marginación, en materia de vivienda (muchas viven en tugurios o en casas desocupadas) y de empleo, por sus bajos niveles educativos (a veces su conocimiento del francés es precario) y de calificación.

\section{IV) LA CRISIS DE LA ESCUELA}

La escuela pública, laica, universal y gratuita ha sido el dispositivo fundamental de asimilación de los inmigrantes dentro y fuera a la cultura francesa, a tono con los valores republicanos de ciudadanía, igualdad y libertad. De hecho, ha sido hasta principios de los años 90 un instrumento para que algunos jóvenes de la inmigración norteafricana lograran una real ascensión social, convirtiéndose en profesionistas, hombres de nego- 
cios, técnicos, etc., recibiendo el apodo de Beurgeoisie ${ }^{3}$ (Castles y Miller, 2004). Un estudio sobre el fracaso escolar de los jóvenes de 2 a. generación descubrió que éstos, a pesar de tener tasas más altas de reprobación en la primaria, acumulaban una ligera ventaja al término de la secundaria respecto de los hijos de franceses «viejos» debido al mayor interés de las familias en el triunfo escolar de sus hijos y al aprovechamiento de los apoyos escolares especiales del gobierno a los alumnos con dificultades culturales (Lorcerie, 1999).

En efecto, a fines de los 70 y en los 80 , se hizo un intento de política educativa bilingüe e intercultural, con cursos de lenguas y culturas de los países de origen, financiados por estos últimos e impartidos por maestros oriundos, para facilitar la integración de los hijos de migrantes y aparentar adoptar el modelo multicultural de moda en los países anglosajones; sin embargo esta política, que no fue masiva, fue rápidamente abandonada cuando los hijos de los inmigrantes se volvieron franceses y sustituida, desde los 90 , por políticas de nivelación de los estándares de calidad de las escuelas a través de apoyos escolares y becas en zonas marginadas, así como la promoción de la pertenencia a una cultura común. (Lorcerie, Ibid.). Sin embargo, esta política no logró impedir los fenómenos de discriminación étnica, de segregación hacia carreras cortas de los hijos de inmigrantes afri- canos $-71 \%$ de los argelinos mayores de 15 años no tenían diploma y sólo $3.1 \%$ tenían bachillerato o algún certificado técnico- (Zehraoui, 1999), y de «guetoización» escolar: a mayor concentración de hijos de extranjeros en la escuela, existían instalaciones más degradadas, más bajos niveles escolares y mayor violencia, lo que acelera el éxodo de los hijos de franceses galos de ellas. A esto, se sumó el conflicto del velo de las jóvenes musulmanas, el cual se prohibió para respetar la laicidad y el carácter mixto de la escuela francesa, pero este triunfo de la opción laicista más conservadora exacerbó los ánimos de la minoría musulmana.

En realidad la institución escolar sufre una crisis profunda, que abarca graves fallas de autoridad y problemas de indisciplina, penetración de conductas anti-sociales y delictivas en los establecimientos, creciente desigualdad de recursos y de personal entre barrios y colegios, inadaptación de los programas y maestros a las realidades de la globalización, hiper-especialización temprana, ${ }^{4}$ etc. No es de extrañar entonces que muchos jóvenes de la banlieue sufran fracasos escolares. Reeve (2006) cita la opinión de un maestro sindicalista: «Uno cree mucho en la escuela, por ser supuestamente un ascensor social. Quemarla es un símbolo de que no funciona. Uno se voltea en contra de ella porque lo decepcionó.»

\footnotetext{
${ }^{3}$ De «Beur», inversión de «árabe», nombre dado a los hijos franceses de la inmigración norteafricana.

${ }^{4}$ De hecho, el ingreso a las Grandes Escuelas hoy es aun menos democrático que hace 20 años. 


\section{V) DISCRIMINACIÓN LABORAL Y DESEMPLEO}

Es en materia laboral donde se pueden observar más claramente los efectos de un racismo indirecto y latente en la sociedad francesa. Desde principios del siglo $x x$ los inmigrantes extranjeros cumplieron un papel económico fundamental en el desarrollo industrial francés, aportando una mano de obra sumisa, barata y flexible que se acomodaba a los ciclos económicos y conllevaba bajos costos por salarios indirectos, pues eran hombres solos en plena edad productiva y que a menudo regresaban a su país en la tercera edad. Se insertaban en la industria automotriz, metalúrgica, química, textil, minera, etc., así como en los servicios públicos y personales de bajo estatus. Desafortunadamente (o no), la revolución post-industrial provocó una reestructuración industrial profunda y eliminó la mayoría de los puestos de trabajo de baja calificación, así como empresas y ramas productivas enteras en donde laboraban estos trabajadores. Por lo tanto, muchos se encontraron desempleados. Al tenor de estas mutaciones económicas, los programas de inmigración laboral legal se cancelaron en 1974, aunque la inmigración legal siguió vía la reunificación familiar, pues la inmigración laboral temporal (en noria) siempre acaba por enraizar en el país de acogida y los migrantes por formar o traer familia allí.

Los hijos de estos inmigrantes ya no podían retomar los trabajos de sus padres, ni querían hacerlo, pues ya habían sido escolarizados en Francia, muchos eran ya franceses y aspiraban a salir del sub-proletariado. Sin embargo, pocos lo lograron pues se toparon con altos niveles generales de desempleo, dificultades para alcanzar niveles educativos superiores y una discriminación generalizada, pero soterrada, en el empleo y en el trabajo. Las crisis económicas y el estancamiento posterior agudizaron la competencia entre franceses blancos de baja calificación y estos «nuevos» franceses de tez morena, nombres impronunciables y caló híbrido, a menudo habitantes de los mismos barrios sórdidos. Esta competencia, que se esquematiza con el miedo de que «esos vienen a robarnos el trabajo", es uno de los factores cruciales de la exacerbación del racismo y del auge del Frente Nacional (Castaingts, op. cit.)

Las elevadas tasas de desempleo son un factor estructural en Francia desde los años 70's, a consecuencia de factores institucionales como la fuerte regulación laboral, los altos impuestos sobre el trabajo, los altos costos de despido contrarrestados por el auge de las contrataciones temporales, un mercado laboral segmentado, la escasa movilidad del trabajo y los desajustes de los niveles de calificación de la fuerza de trabajo, etc. (Pérez Pérez, 2006). Así, la tasa de desempleo fue mucho tiempo superior al $10 \%$ y en 2005 todavía era de 9.8\% (6o. peor lugar de la Unión Europea) (Pérez Pérez, Ibid.). En este sentido la situación es bien diferente a la de Estados Unidos e Inglaterra, en donde habían tasas de desempleo de menos de la mitad y todos los inmigrantes, legales o no, encuentran trabajo. El desempleo afecta espe- 
cialmente a los jóvenes, a los mayores de 55 años y a los trabajadores poco calificados.

Es, en los suburbios de las grandes ciudades, donde el desempleo hace sus mayores estragos: $21 \%$ de parados frente a $10 \%$ en promedio nacional y alcanza $26 \%$ en la zona noreste de $\mathrm{Pa}$ ris en donde empezaron los motines (Boils, 2006). Pero este flagelo se ensaña más con los jóvenes de origen magrebí: en 1992, los de origen argelino alcanzaban una tasa de $40 \%$ frente a una de $11 \%$ para los jóvenes franceses nacidos de padres franceses, e incluso los diplomados beurs padecían sobreparo. Es evidente el papel jugado por el factor de discriminación laboral (Tribalat, 1999). En 1996, 26.5\% de los hombres y $36 \%$ de las mujeres argelinos estaban desempleados (Zehraoui, 1999). En efecto, en las contrataciones es muy común que los empleadores nieguen el empleo por el color de la piel, el apellido o el lugar de residencia; se presume que los hijos de trabajadores inmigrados son difíciles de integrar a la disciplina de las empresas, como lo declaró abiertamente la dirigente de la organización patronal francesa: «La cultura de la banlieue es antinómica con la cultura de la empresa». En Clichy-sous-Bois, donde prendió la mecha, el desempleo llegaba a 40\%. (Reeve, op. cit.).

En este contexto, y con un estado de bienestar en crisis financiera, las políticas sociales en materia educativa, de salud y de subsidios financieros «se revelan insuficientes para la integra- ción social cuando existen barreras en el empleo construidas por el prejuicio y la estigmatización por raza, etnia o religión.» (Rincón Gallardo, 2005).

\section{VI) EL IMPACTO DEMOGRÁFICO DE LA INMIGRACIÓN EN FRANCIA}

En 1999 había en Francia 4’310,000 residentes extranjeros $(7.4 \%$ de la población), pero más de un millón y medio de antiguos inmigrantes se habían naturalizado en las últimas décadas y medio millón eran ciudadanos de color provenientes de los DOM-TOM. ${ }^{5}$ Los principales países de origen de los extranjeros eran Argelia $(576,000)$, Portugal $(570,000)$, Marruecos $(521,000)$, Italia $(380,800)$, España $(316,500)$, Túnez $(201,700)$ y Turquía $(176,000)$. Francia tenía la población musulmana más importante de Europa: 2.5 millones, en 1990 y serían 5 millones, en 2007.

Entre 1980 y 2000 , entraron un promedio de 54,5000 extranjeros legales cada año, lo que representó sólo el $0.01 \%$ de una población total de 62.7 millones de habitantes en 2007; aunque a fines de los $90 \mathrm{y}$ principios de los 2000 los inmigrantes representaron casi el doble de esa cifra. La mayoría (más de $2 / 3$ partes) lo hicieron por medio de la reunificación familiar, luego por matrimonio, después por solicitud de asilo y sólo $12 \%$ por razones laborales (Le Monde, 2006).

A pesar de no ser entradas masivas, la inmigración representa el 25\%

\footnotetext{
${ }^{5}$ Departamentos de Ultra-Mar y Territorios de Ultra-Mar. 
del aumento demográfico total debido al muy bajo crecimiento demográfico natural y contribuye a contrarrestar el envejecimiento acelerado de la población y, a mediano plazo, de la PEA, ya que además, las familias inmigrantes tienen 35\% más hijos, que las francesas (Boils, op. cit,). A pesar de no representar amenaza alguna al predominio de los «galos» en el futuro próximo, esta tasa de fecundidad inquieta a los sectores derechistas franceses y pesa sobre los servicios públicos de atención social.

Se estima en 500,000 el número de los indocumentados en Francia, de un total de 3 millones en toda la Ue y en alrededor de 10 a 20,000 entradas ilegales al año (0.03\% de la población); se trata, en su mayoría, de hombres adultos de baja calificación que laboran en la economía informal (servicio doméstico, confección, construcción, agroindustria y agricultura) en condiciones de sobreexplotación y, a veces, de casi-esclavitud, o bien de personas que sobreviven entre el desempleo, la venta callejera y pequeños tráficos. Estos migrantes ilegales han llevado a cabo luchas en los años 90 ocupando iglesias y haciendo huelgas de hambre -el movimiento de los sans-papiers o «sin papeles»- logrando algunas regularizaciones bajo los gobiernos socialistas, pero que desde 2002 han sido perseguidos y deportados de manera sistemática. El gobierno francés se queja de que los gobiernos español e italiano toleran esta inmigración clandestina que luego puede pasarse a Francia.

\section{VII) CRISIS DE LA POLIITICA DE INTEGRACIÓN}

La revuelta de los jóvenes de la periferia urbana y social de Francia es el producto de un agotamiento de la capacidad de asimilación económica y cultural de las instituciones, así como de las políticas de control y represión policial cada vez más opresivas. «La crisis es la crisis de la institución republicana francesa: la república francesa dice a todos «libertad, igualdad, fraternidad» es una promesa maravillosa, pero no vale para todos, y cuando eres joven, instruido y sabes que el sistema escolar va a ser un sistema segregativo de hecho, no en teoría, esto te va a crear una frustración muy fuerte; esta es la única crisis en Europa de estas dimensiones, una crisis de todas las instituciones: esto vale para la justicia, para la policía, pero el lugar institucional central es la escuela» (Wieviorka, 2006).

En efecto, las instituciones sociales y políticas están en crisis: el sistema de seguridad social, uno de los más avanzados del mundo, registra un grave déficit en el régimen de jubilaciones y seguro médico debido al envejecimiento de la población y a las jubilaciones anticipadas. La justicia está saturada de juicios penales que no logra desahogar y está desarmada ante la cada vez más joven edad de los delincuentes, que por lo mismo no puede mandar a la cárcel y no sabe cómo tratar. La policía carece de medios suficientes para enfrentar el incremento de la delincuencia. La familia se desintegra por los divorcios, la ruptura padres-hijos y los hogares monoparenta- 
les crecientes. La integración cultural nacional está amenazada por la creciente americanización de las costumbres y por el peligro de encierro comunitarista de las minorías étnicas que, al sentirse discriminadas buscan afirmar su identidad mediante la conversión religiosa, en particular musulmana, que a veces se orienta hacia el integrismo o politización del Islam como expresión de protesta.

En el otro extremo se exacerban las actitudes racistas y las opiniones políticas xenofóbicas que se traduce en el auge electoral del Frente Nacional y otros partidos derechistas.

La república francesa era la maquinaria de la integración; se rompió y lo hicieron todas sus piezas juntas: el ejército, la familia y la escuela, que eran los elementos que transmitían una cultura patriótica. Lo mismo ocurrió con la iglesia, los partidos y los sindicatos. El estado de derecho no puede vivir sin valores comunes, pues el ciudadano se identifica con sus congéneres por modelos que ahora no existen; de ahí que surjan identidades inconscientes de tipo religioso o étnico que rebasan el sentimiento de ciudadanía republicana (...) De donde surge el vértigo y la sublevación anárquica, como expresión de una frustración. (Debray, 2005, cit. por Cruz Zamorano, 2006).

Sin embargo, los hijos de inmigrantes norteafricanos buscaron integrarse a la cultura francesa, varios se casaron con francesa(e)s de origen y las instituciones los estimularon a integrarse. La política de naturalizacio- nes francés, que privilegia el jus soli sobre el derecho de sangre que sigue Alemania, así como el régimen de acogida de refugiados, fue muy benévola en los años 80, la escuela se abrió a ellos tratando de adaptarse a sus problemas, pero el país entró en recesión económica, cundió el desempleo y los hijos de inmigrantes fueron estigmatizados por un racismo creciente $\mathrm{y}$ "se convirtieron en ciudadanos de segunda: Francia no ha podido integrarlos ni a la sociedad, ni a la política, ni a la economía» (Cruz Zamorano, Ibid). Estas nuevas generaciones de franceses han sido víctimas de un racismo soterrado en todos los frentes: institucional -veto al velo en las escuelas-, cultural-discriminación laboral que sufren en el sector privado-, en la vivienda -dificultades para alquilar un departamento- y un racismo político -las agresiones y crímenes racistas(Bataille, 1999).

El destino de la mayoría de ellos ha sido la "asimilación descendente» (Portes y De Wind, 2006), al no poder incorporarse a las estructuras normativas de la clase media, por falta de capital humano y monetario paterno, así como por su estructura familiar estallada, ni tampoco incorporarse a las redes étnicas transnacionales que proporcionan apoyo familiar y comunitario a los jóvenes, mantienen valores culturales y pautas de conducta del país de origen distintas de las dominantes en el país receptor y que logran crear mercados laborales étnicos y alcanzar un cierto bienestar económico (García Borrego, 2006). En efecto, la gran mayoría de ellos están muy acul- 
turados, pues sólo 24\% de los hijos de parientes argelinos podían hablar la lengua de sus padres, sólo 14\% de los hijos de padres argelinos practicaban regularmente la religión musulmana y el 50\% de los hijos nacidos en Francia habían tenido su primera unión con francesas de origen. No obstante, en las periferias urbanas esta aculturación no se ha traducido en una adopción plena de la cultura francesa, es una cultura «de segunda»: «su cultura es americanizada, es la "gangsta rap» ligada al hip-hop: usan la misma ropa, los mismos gestos, los mismos videojuegos, escuchan la misma música y se organizan en bandas similares (a las de EUA)» (Castaingts, op. cit.), de hecho están orillados a una cultura de la violencia.

La terrible trampa y contradicción del hijo de los inmigrantes de origen africano es que, aun cuando se integra y se acultura, «sigue siendo considerado inferior en la sociedad francesa porque es diferente $y$, por otro lado, se cortó de su medio de origen. Así es doblemente culpable de traición: pertenece a su grupo de origen, sin pertenecer realmente a él, y pertenece a la sociedad receptora, sin pertenecerle» (Lapeyronnie, 1999). Para él es más difícil enfrentar la discriminación que para sus padres, pues nació en Francia y ya no tiene nexos con los lugares de origen de sus padres: y no puede refugiarse en sus orígenes (Ibid.). En reacción, trata de construir su identidad exacerbando su diferencia, por ejemplo en el Islam radical, y reclama reconocimiento de su identidad fundada en su experiencia (conflictiva) de la sociedad de acogida (Ibid.): esto genera dificultades con la policía, manifestaciones de «racismo al revés» y explosiones de violencia callejera.

\section{VIII) ANTECEDENTES POLÍTICOS DE LA RE- VUELTA Y FACTORES PRECIPITANTES}

Los suburbios de Paris eran el «cinturón rojo» de la capital, pues el Partido Comunista (PC) tenía el control social y político de estos municipios. Desde los años 80, el PC, se debilitó tanto, que estuvo al grado de casi desaparecer de la región dejando un gran vacío organizacional y un déficit de políticas social y de vivienda popular. Buena parte de su base social obrera se pasó al Frente Nacional. Esto sentó las bases para la división del proletariado entre franceses de origen y de adopción.

El sentimiento de frustración y la tentación de la violencia de los herederos de la migración fue canalizado, en los años 80, hacia vías cívicas y políticas. En efecto, después de los primeros motines suburbanos, se generó un gran movimiento anti-racista que movilizó en 1983, bajo el gobierno socialista, a franceses y jóvenes beurs en una gran marcha de 100,000 personas de Marsella a Paris para demandar la igualdad de derechos y al mismo tiempo el derecho a la diferencia cultural, con orientaciones que mezclaban ideales republicanos y formas de organización y de cultura comunitarias (Wihtol de Wenden, 1999). Los manifestantes expresaban su deseo de interlocución política, más allá una ciu- 
dadanía plena y participativa, desde lo local a lo nacional, incluso presentaron candidatos a las elecciones municipales. El presidente Mitterand los recibió, les otorgó permiso de residencia y de trabajo por 10 años, naturalizó a muchos pero, a cambio, el gobierno y el partido socialista trataron de recuperar políticamente al movimiento, cooptando a los líderes asociativos, cortándoles de su base social y neutralizando su potencial radical. La tradición de lucha anti-capitalista se perdió con la derrota de las últimas huelgas de obreros inmigrados, que no concitaron el apoyo de los obreros sindicalizados franceses, ni conectarse con las luchas ciudadanas de sus hijos.

(Dell'Umbria, 2006).

En los años 90's vino la resaca y el desencanto de los activistas beurs antiracistas debido a la falta de voluntad política del gobierno socialista por abrirles las puertas del sistema político. Ante la decepción provocada por la izquierda y por el movimiento anti-racista beur, que sólo atacaba un aspecto de la exclusión social, el racismo, pero no lograba cambiar la realidad económica cotidiana de los jóvenes (Ibid). Los activistas beurs perdieron legitimidad y fueron desplazados por las asociaciones islámicas, algunos incluso se reconvirtieron al comunitarismo musulmán que rechaza la integración: «el movimiento asociativo tuvo que reubicarse o desaparecer» (Wihtol de Wenden, 1999). A fines de los 90 surgió el movimiento de los sans-papiers, que a pesar de que logró movilizar solidaridades entre intelectuales france- ses, ONG's y la Iglesia, no alcanzó la gran unión entre jóvenes franceses de origen y franceses de la inmigración de los 80 .

El proceso de integración sociocultural siguió su curso, aunque con modalidades híbridas -los jóvenes se integran culturalmente sin abandonar del todo su identidad familiar- pero la inserción económica quedó rezagada por el alto desempleo, lo que creó un terreno fértil para el comunitarismo diferencialista (Wihtol de Wenden, 1999) o las explosiones de ira espontáneas. En efecto, «hoy ya no hay movimiento obrero (ni ciudadano) ni partido político que politice el sentimiento de frustración y rabia de estos jóvenes y sus revueltas tienen carácter autodestructor» (Noiriel, 2002).

La política del gobierno derechista de Jacques Chirac y Nicolás Sarkozy iniciado en 2002 agudizó este sentimiento de agravio moral, al reducir los programas sociales y aumentar las medidas represivas y de seguridad. Por ejemplo, suprimió los «empleos-jóvenes» subsidiados por los gobiernos locales, que daban trabajo de mediadores sociales a los jóvenes de $2 \mathrm{a}$ generación de las banlieues; contrajo los presupuestos para la salud pública en zonas pauperizadas y aumentó las cuotas a los pacientes; canceló los apoyos económicos a las asociaciones de trabajadores sociales de barrio y liquidó la policía de proximidad, que había ganado la confianza de la población por estar radicando en los barrios con problemas. Su política de la ciudad se resumió en incrementar la vigilancia 
policial y la lucha contra el terrorismo y la delincuencia, prohibir a los jóvenes reunirse en la entrada de las torres para «evitar las pandillas» -en realidad para impedir que se reúnan, piensen y actúen colectivamente-, abandonar los programas de rehabilitación de inmuebles que ocasionó accidentes en los grandes conjuntos habitacionales debido a su deterioro, provocando la muerte de 60 personas. En este clima se recrudecieron las agresiones racistas, pues dos meses antes de la revuelta, ocurrió un incendio presuntamente intencional en un inmueble habitado por migrantes, causando la muerte de 14 personas, entre ellas dos niños, después de otros dos incendios de casas ocupadas por migrantes, que tuvo un saldo de 24 africanos muertos en el mismo municipio de las afueras de París.

Junto a una política migratoria restrictiva y a una política de seguridad muy dura, Sarkozy implementó una política comunitarista al estilo americano en materia de integración. Con ella, el gobierno apoyó la construcción de mezquitas y reconoció como interlocutores a todos los líderes religiosos musulmanes, incluidas algunas asociaciones integristas sin mucha representatividad, para tratar de controlarlos. El ministro del Interior y hoy, por desgracia, presidente de la República parece inspirarse más del multiculturalismo anglosajón, que ha sido cuestionado y parcialmente abandonado en los mismos Estados Unidos, que del crisol republicano homogeneizador, asimilacionista y laico.

\section{IX) PISTAS PARA DESCIFRAR EL SIGNIFICADO DE LA REVUELTA}

Se trató de una demanda de reconocimiento por parte de estos jóvenes de su ser social y político, de su dignidad en contra de los atropellos constantes de la policía, que los detiene sistemáticamente por su fenotipo, y a veces los golpea o mata "por error", sin ser casi nunca castigada. Los jóvenes buscaban un reconocimiento de su calidad de ciudadanos como cualquier otro, con los mismos derechos al trabajo, al consumo, a la cultura y a la diversión, sin tener que ser marginados por su raza o su origen. «La reivindicación de los jóvenes de 2 a generación es ser ciudadanos plenos en su diversidad, y no pertenecer a tal o cual grupo comunitario, étnico o religioso» (J. Ralite, senador comunista de Seine St. Denis, 2005). "Lo que no soportan es el desfase entre la teoría y la práctica, entre el lema de la igualdad republicana y el destino de desempleo. (...) Lo único con lo que sueñan es tener dinero para consumir como los demás.» (Bouzour, 2005).

La ausencia de antecedentes penales de los arrestados durante los disturbios impide interpretar el movimiento como un intento de control del territorio por parte de bandas del narcotráfico contra el Estado u otras bandas. El factor religioso tampoco es explicativo de esta revuelta, pues no hubo ninguna dimensión islámica en esta violencia (Wieviorka, op. cit.); incluso algunas asociaciones musulmanas quisieron crear milicias de protección contra las violencias y fueron repudiadas por los revoltosos. Lo mismo ocurrió con las organizaciones de 
izquierda, que no tuvieron nada que ver con la organización de la revuelta, ni la previeron, ni la entendieron. Esto puede explicar en parte la ausencia de programa político del movimiento cuya única demanda a veces formulada, porque estos rebeldes casi no hicieron declaraciones públicas, era la destitución de Sarkozy. También explica la ausencia de utopía social y de enlaces con otros sectores populares de la sociedad. En todo caso los blancos de sus ataques no dejan duda de que sus demandas y rencor iban dirigidos a las instituciones del Estado.

El perfil socio-demográfico y socio-económico de estos jóvenes aporta luces sobre la naturaleza del movimiento: $50 \%$ de los detenidos eran menores de edad, la gran mayoría tenían de 14 a 22 años, algunos apenas tenían 11 años. Ello explica, por ejemplo, el carácter lúdico de los incendios desatados por adolescentes desocupados y sin actividades recreativas, así como la emulación que crea la cobertura mediática entre barrios y ciudades por "salir en la tele con más quemazones». El 33.2\% de los detenidos sólo contaban con nivel educativo de primaria y muchos estaban en situación de fracaso escolar, lo que explica su falta de expectativas en la escuela. Los consignados, que no eran alumnos, tenían empleos precarios y mal pagados: mensajeros, diableros, cargadores, panaderos, etc. (Jeremie, 2006), o sea, eran parte del subproletariado.

Según una encuesta realizada en 2006 por el sociólogo H. Lagrange, en los barrios más conflictivos del otoño caliente, los factores más constantes relacionados con estas colonias son:
- Alta tasa de desempleo de los jóvenes.

- Pirámide demográfica de ancha base: los niños y adolescentes pueden representar más de $35 \%$ de la población.

- Muy alta tasa de familias numerosas (más de 6 personas por familia, en particular en familias procedentes de África negra, con muchos hijos y pocos recursos): esto suele propiciar problemas familiares graves, pues $83 \%$ de los involucrados en los motines viven en departamentos de interés social chicos: "Viven hacinados; cuando crecen hay conflictos con los hermanos. Los ingresos familiares son pocos y no queda dinero para que puedan divertirse» (M. Lahtifi, educador, 2005). Según Lagrange esta combinación explosiva es la variable más significativa.

- Barrios pobres en ciudades ricas: los jóvenes resienten el contraste social todos los días.

- Colonias con viviendas muy deterioradas, destinadas a demolición.

- Hubo sobre-representación de jóvenes negros entre los insurrectos, lo que se puede relacionar con la relación superficie de vivienda/ personas por familia (Lagrange, Le Monde, 2006).

\section{CONCLUSIÓN}

En conclusión, podemos ver estos tumultos como un estallido de furor irracional, donde entran a actuar mecanismos psicológicos de «regreso del estigma» (Morice, op. cit.) cuando las víctimas de la discriminación retomen 
a su cuenta las marcas estigmatizantes que las señalan con el dedo y las reivindican (los tachados de violentos como los chavos-banda se vuelven más violentos, los denostados como indios o negros proclaman su negritud y su indianidad). Este mecanismo fue analizado por Frantz Fanon, en el caso de los colonizados, en "Los Condenados de la Tierra».

- Otra interpretación es la de Wieviorka, que se refiere a un sujeto flotante que no alcanza a transformarse en actor, a insertarse en una relación social, política o intercultural, y que se siente negado como sujeto, no reconocido. Esto lo puede llevar a conductas de rabia, de destrucción o de auto-destrucción cuando es agraviado personalmente o en su grupo por un abuso policial o una injusticia de la Justicia. Esta violencia puede fundar el sujeto en ciertos casos, actuando como catarsis que arranca al individuo de una cotidianeidad pasiva y alienada, desencadenando un proceso de subjetivación que puede, a partir de un sentimiento de solidaridad espontáneo, ser el primer paso para comprometerse en asociaciones cívicas, culturales, deportivas o políticas, o el inicio de una carrera delictiva y anti-social (Wieviorka, 2005).

- Pero también se pueden leer estos disturbios como una revuelta social pre-política, anti-autoritaria más que anti-capitalista, y por un reconocimiento, una igualdad real de oportunidades y un respeto a las diferencias, contra una sociedad y un estado que excluyen y humillan a sus hijos bastardos, después de haber explotado y relegado a sus padres. Contra la violencia económica y la violencia cotidiana policiaca, la violencia ejercida por los excluídos es salvaguarda del sujeto, liberadora, al menos por un tiempo. «La violencia del sujeto encuentra su espacio en el déficit, las lagunas, la descomposición de los conjuntos societales a todos los niveles, de lo más local a lo más global» (Wieviorka, 2005).

\section{BIBLIOGRAFÍA}

Bataille, Philippe (1999), «Racisme institutionnel, racisme cultural et discriminations», en Immigration et Intégration: l'état des saviors, Paris, Edit. Dewitte, La Découverte.

Body-Gendrot, Sophie (1999), «Ghetto, mythes et réalités», Immigration et Integration: l'état des saviors, Paris, Edit. Dewitte, La Découverte.

BoILs, Guillermo (2006), «Vivienda y exclusion social en la periferia de Paris», Revista de Investigación Social, México, Instituto de Investigaciones Sociales, UNAM, núm. 2, verano.

Bouzour, Dounia (2005), «La religión no tiene la culpa", México, Reforma, 20 de noviembre.

Bruneau, Michel (2004), Diasporas et espaces transnationaux, Paris, Anthropos.

CAstaingts, Juan (2005), "Así vamos... Tumultos sociales en Francia», El Financiero, México, 17 de noviembre.

Castles, Stephen y Mark Miller (2004), La Era de la migración, México, Miguel Ángel Porrúa, Instituto Nacional de Migración, Universidad Autónoma de Zacatecas. 
Cruz Zamorano, Alma Rosa (2006), «Francia, desempleo, inmigración y violencia», México, Comercio Exterior, vol. 56, núm. 4, abril.

Dell'umbria, Alessi (2006), "C'est la racaiHe, eh bien, j'en suis», Paris, Edit. L'Echappée.

Fanon, Frantz (1961), Les Damnés de la terre, Maspero.

García Borrego, Iñaki (2006), «Generaciones sociales y sociológicas: un recorrido histórico por la literatura sociológica estadudinense sobre los hijos de inmigrantes», Migraciones Internacionales, Tijuana, México, núm. 11, julio-diciembre.

Jeremie, Charles (2006), "A propos d'une révolte populaire des cités», Carré Rouge Paris, núm. 35, marzo.

Lagrange, Hugues (2006), "On Pert lire les violences comme une demande d'Etat de la jeunesse», Paris, Le Monde, 7 de junio.

LapeYronnie, Didier (1999), "De l'altérité a la difference. L'identité, facteur d'intégration ou de replie, Immigration et Intégration: l'état des savoirs, Paris, Edit. Dewitte, La Découverte.

Le Monde (2004), «Les R.G. s'alarment d'un repli communautaire dans les banlieues», Paris, 5 de julio. (2006), «L'immigration en Europe: durcissement quasi general», Paris, 7 de junio.

LORCERIE, Francoise (1999), «La scolarisation des enfants de migrants: fausses questions et vrais problemas", Immigration et Intégration, l'etat des savoirs, Paris, Edit. Dewitte, La Découverte.

Morice, Alain (2005), «Les émeutes urbaines d'octobre-novembre 2005 en France: comprendre avant de juger», Revista electrónica Pajol, http//pajol.eu.org/article905.html.
NoIRIEL, Gerard (2002), «Petite histoire de l'intégration a la francaise", Maniere de Voir No. 62, Paris, Le Monde Diplomatique, marzo-abril.

Pérez Pérez, Gabriel (2006), «El problema del trabajo y el estado de bienestar en la Unión Europea», México, El Cotidiano, núm. 136, marzo-abril.

Portes, Alejandro y Josh De Wind (2006), "Un diálogo transatlantico: el progreso de la investigación y la teoría en el estudio de la migración internacional», Repensando las migraciones, en Portes, Alejandro y Josh De Wind (editores), México, Miguel Ángel Porrúa, Universidad Autónoma de Zacatecas, Instituto Nacional de Migración.

Quiminal, Catherine (1999), «Les Africains, divers et dynamiques», Immigration et integration: l'état des saviors, Paris, Edit. Dewitte, La Découverte.

RALITE, Jack (2005), Intervention au Sénat sur le projet de loi prorogeant l'application de la loi No. 55-385 du 3 avril 1955, 16 de noviembre.

ReEve, Charles (2006), Incendies sans paroles, Paris, Carré Rouge, núm. 35, marzo.

Rey, Henri (1999), «La peur des banlieues», Immigration et Intégration: l'état des savoirs, Paris, Edit. Dewitte, La Découverte.

Rincón Gallardo, Gilberto (2005), «Enseñanza francesa», México, Reforma, 12 de noviembre.

TodD, Emmanuel (1994), Le destin des immigrés, Paris, Seuil.

Tribalat, Michele (1999), «Définir, quantifier, sérier les mécanismes d'intégration", Immigration et Intégration: l'état des savoirs, Paris, Edit. Dewitte, La Découverte.

Wieviorka, Michel (2005), La Violence, Paris, Hachette Litteratures, Pluriel. 
(2006), Entrevista, México, Departamento de Sociología, UAM-Azcapotzalco, 20 de octubre.

Wihtol de Wenden, Catherine (1999), «Les jeunes issus de l'immigration entre intégration culturelle et exclusión sociale», Immigration et Intégration, l'état des savoirs, Paris, Edit. Dewitte, La Découverte.

Zehraoui, Ahsene (1999), «Les Algériens, de la migration a l'installation", e Immigration et Intégration, l'état des savoirs, Paris, Edit. Dewitte, La Découverte. 
PARTICIPARON COMO DICTAMINADORES DURANTE 2007

\author{
Katharine Andrade EeKHoff \\ Universidad Centroamericana José Simeón Cañas (UCA) \\ María Eugenia Anguiano Téllez \\ El Colegio de la Frontera Norte \\ Cristina Blanco F. de Valderrama \\ Universidad del País Vasco - Euskal Herriko Unibertsitatea \\ Leticia Calderón Chelius \\ Instituto de Investigaciones José María Luis Mora
}

Rodolfo García Zamora

Universidad Autónoma de Zacatecas

LUIN GOLDRING

York University

Gioconda HerRera

Flacso-Ecuador

Fernando Lozano Ascencio

CRIM/UNAM

Miguel Moctezuma Longoria

Universidad Autónoma de Zacatecas

Oscar Pérez VeYna

Universidad Autónoma de Zacatecas

Rafael G. Reyes Morales

Instituto Tecnológico de Oaxaca

Ofelia Woo

Universidad de Guadalajara

Patricia Eugenia Zamudio Grave

CIESAS-Golfo

Víctor A. Zúñiga González

Universidad de Monterrey 


\title{
Publicaciones
}

\section{FRONTERA NORTE}

estudios ambientales, culturales, de población, de administración pública, económicos, sociales

\author{
Potencial de desarrollo y gestión de la política regional: \\ El caso de Chihuahua \\ Luis Enrique Gutiérrez Casas \\ La frontera en la comunidad imaginada del siglo XIX \\ Enrique Rajchenberg S. y Catherine Héau-Lambert
}

¿Una educación indígena intercultural para la ciudad?: El Departamento

de Educación Indígena en Nuevo León

Séverine Durin

Envejecimiento y migración en Baja California

Elmyra Yaáñez Zepeda y Rafael Alarcón

Ciudad de muros: Socialización y tipología de las urbanizaciones

cerradas en Tijuana

Jesús Ángel Enriquez Acosta

Financiamiento de infraestructura ambiental en la frontera

México-Estados Unidos: La estrategia del BDAN

Liz lleana Rodriguez Gámez

Proveeduría nacional a la industria maquiladora en México:

Un reto tecnológico

Juan Óscar Ollivier Fierro

\section{El Colegio
de la Fronter \\ 17 derte}

Frontera norte es una publicación bilingüe, editada semestralmente

por El Colegio de la Frontera Norte con el fin de difundir trabajos de investigación que aborden la problemática fronteriza en México o en otros contextos.

El Colegio de la Frontera Norte, Carretera Escénica Tijuana-Ensenada km. 18.5,

San Antonio del Mar, C.P. 22560,

Tijuana, Baja California, México, http://www.colef.mx/fronteranorte/index2.asp 


\section{Publicaciones}

International Migration Review is an interdisciplinary peer-reviewed journal created to encourage and facilitate the study of all aspects of sociodemographic, historical, economic, political, legislative and international migration. It is internationally regarded as the principal journal in the field facilitating study of international migration, ethnic group relations, and refugee movements.

Through an interdisciplinary approach and from an international perspective, IMR provides the single most comprehensive forum devoted exclusively to the analysis and review of international population movements.

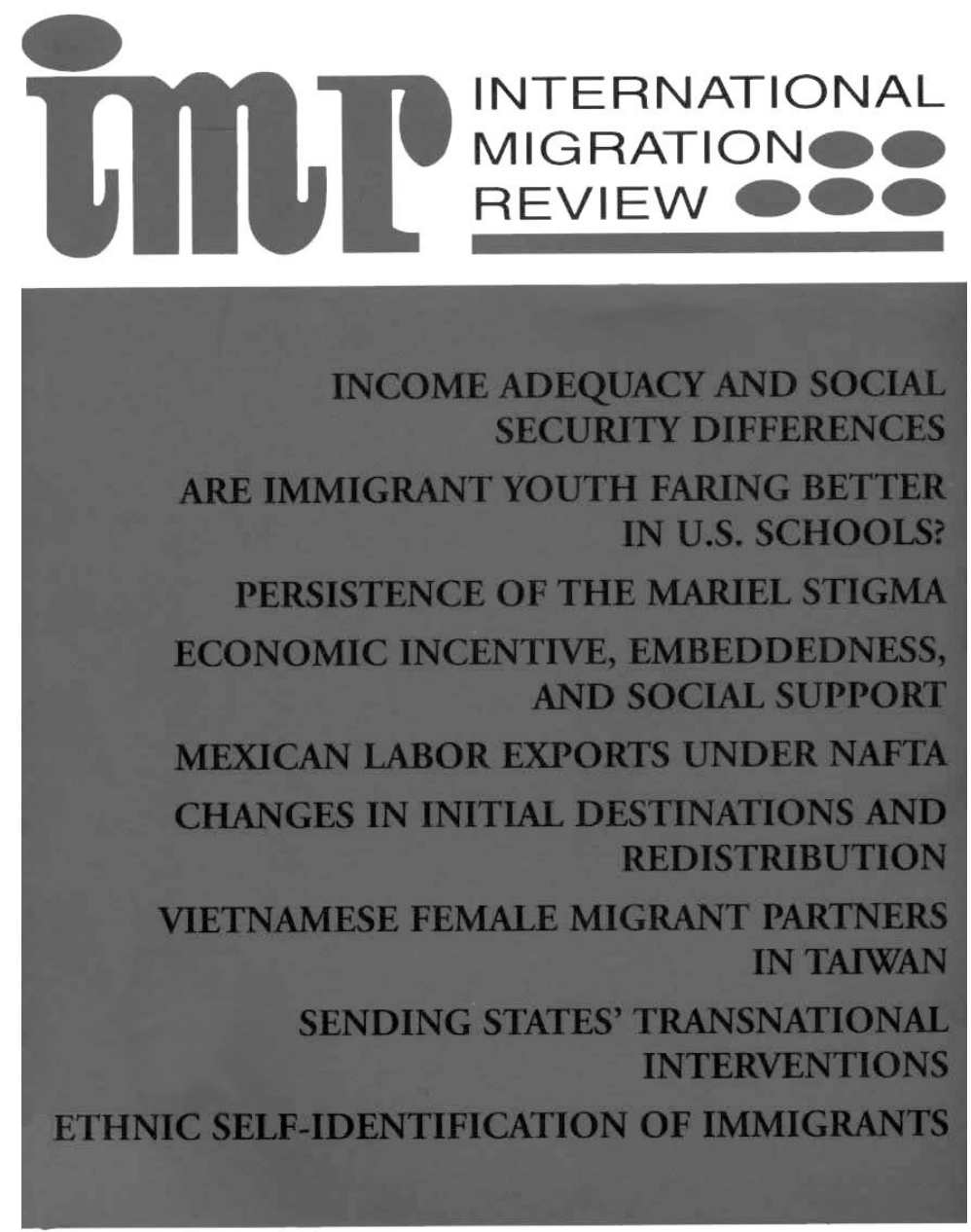

Vol. 41, No. 3, Fall 2007 CENTER FOR MIGRATION STUDIES

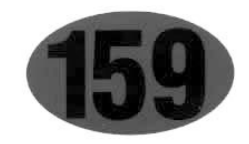




\section{Publicaciones}

\section{Migraciones IN TER NACIONALES}

Mujeres expatriadas en México: trabajo, hogar y vida cotidiana Anna Ortiz Guitart y Cristóbal Mendoza

Jefaturas de hogar. El desafio femenino ante la migración transnacional masculina en el sur del Estado de México Mariela Loza Torres, Ivonne Vizcarra Bordi. Bruno Lutz Bachere y Eduardo Quintanar Guadarrama

Negocios remeseros en Gabriel Leyva Solano. Una localidad sinaloense de reciente migración

Enka Montoya Zavala

La economia de Tlapanalá

Miguel Angel Corona Jiménez

Asociaciones politicas de inmigrantes peruanos

y la "Lima Chica" en Santiago de Chile

José Carlos Luque Brazán

Los vinculos afectivos y de cuidado en las familias transnacionales Migrantes ecuatorianos y peruanos en España

Sonia Parella

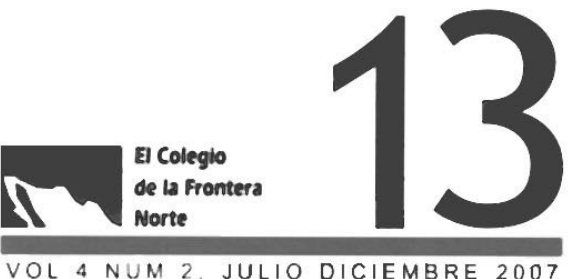

Migraciones Internacionales es una revista de investigación científica con arbitraje, de publicación semestral, que difunde trabajos sobre migración internacional en todo el mundo, en español e inglés.

Publicada por El Colegio de la Frontera Norte, Carretera Escénica Tijuana-Ensenada km. 18.5, San Antonio del Mar, C.P. 22560, Tijuana, Baja California, México. http://www.colef.mx/migracionesinternacionales/index.asp 
+)

\section{Publicaciones}

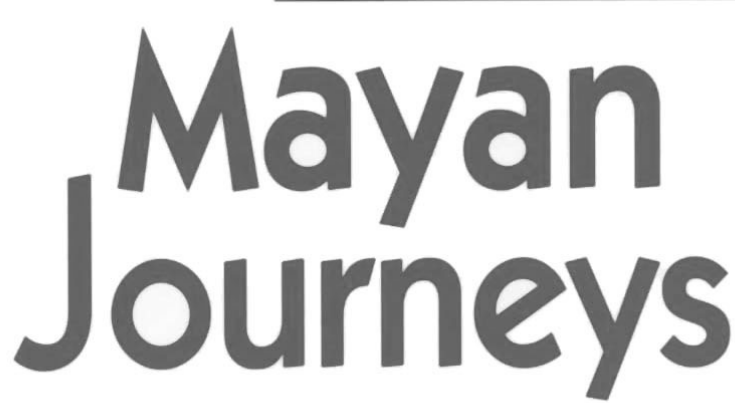

THE NEW MIGRATION FROM YUCATÁN TO THE UNITED STATES

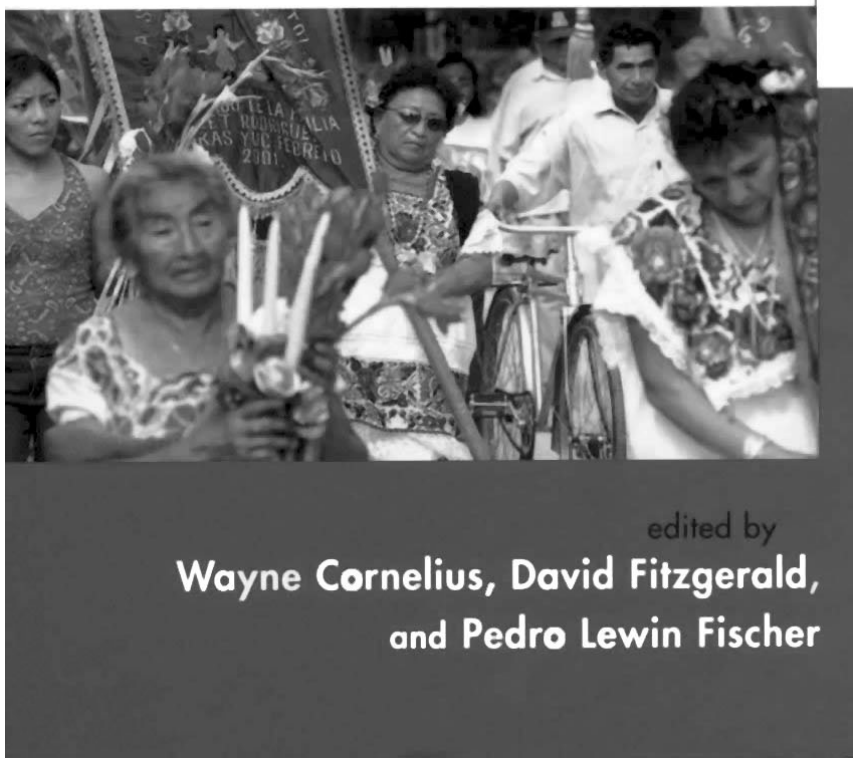

Los migrantes indígenas del sur de México están cambiando visiblemente el perfil de los flujos migratorios hacia Estados Unidos. Tomando en cuenta la larga historia de la migración mexicana hacia los Estados Unidos, żpor qué las comunidades indígenas del sureste tomaron tanto tiempo para entrar en las corrientes migratorias? ¿Cómo difieren las experiencias migrantes indígenas de las experiencias de los migrantes mestizos que caracterizaron las anteriores olas migratorias originarias de la región centro occidente de México?

El libro presenta las respuestas encontradas por los autores en su viaje a Tunkás Yucatán y dan seguimiento a las distintas olas migratorias que pasaron de lo local a lo regional, hasta conectarse con los circuitos migratorios hacia Estados Unidos para integrarse a la fuerza laboral de aquel país... 


\section{Publicaciones}

Esta obra muestra una antología crítica y comentada que busca suscitar preguntas

y cuestionamientos que lleven a la investigación de nuevos temas y problemas en torno a un tema crucial: los programas de trabajadores temporales.

Todos los autores recuperados en esta antología coinciden en que

el Programa Bracero representó un avance en comparación con la situación anterior, es decir, con la época del enganche. También concuerdan en considerar que el programa significó una mejora en la situación laboral de los braceros en relación con "los mojados" que no contaban con la protección

del gobierno mexicano, no había normas contractuales de trabajo. La situación de los braceros tampoco fue la panacea y las condiciones de trabajo, alimentación, salud y vivienda siempre fueron críticas, salvo honrosas excepciones.

Pero, paradójicamente, la situación de los trabajadores migrantes hace medio siglo fue sustancialmente mejor que las de los trabajadores indocumentados del siglo XXI.

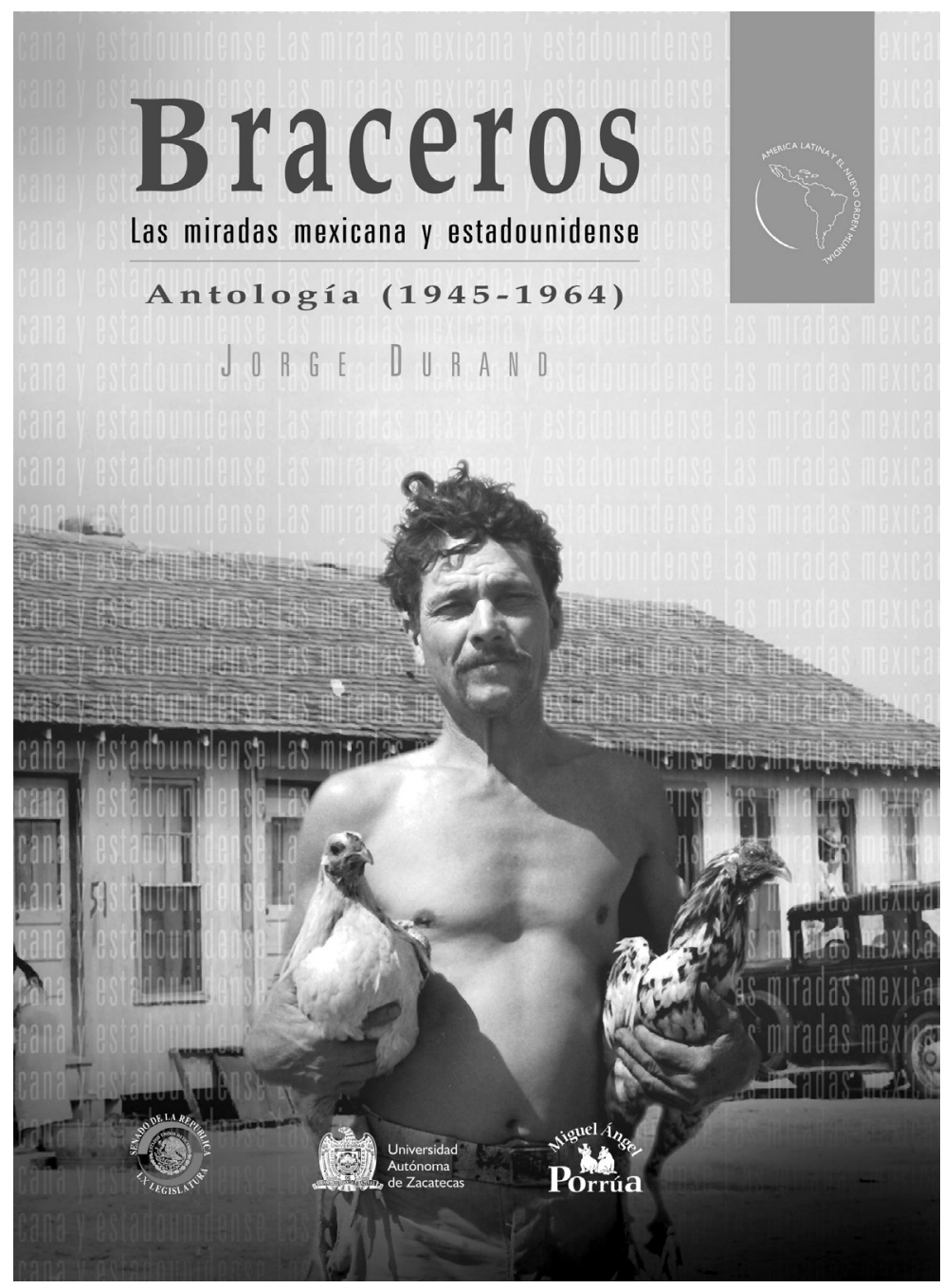




\section{Publicaciones}

\section{Migración y desarrollo:}

perspectivas desde el sur

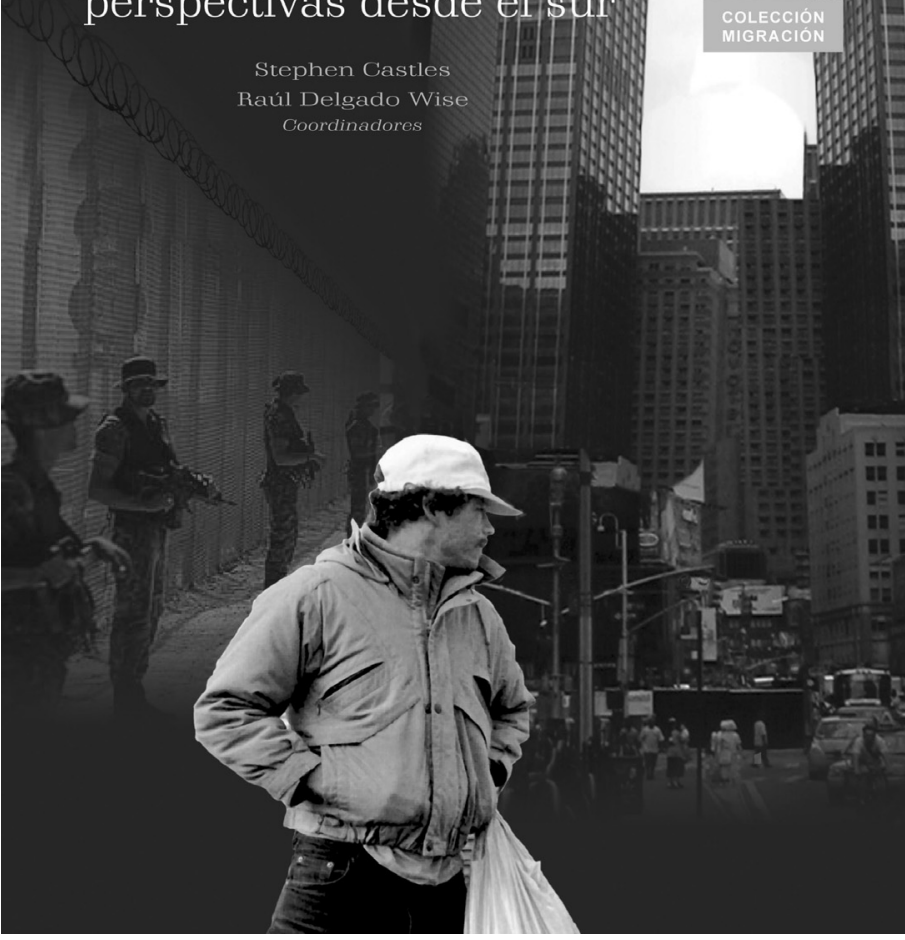

La relación entre migración y desarrollo es un tema clave para la investigación académica y para la definición de políticas. Algunas viejas perspectivas se enfocaban en el riesgo que la pérdida de recursos humanos representaba para el desarrollo de los países pobres. Actualmente, está en boga una visión más optimista definida por los gobiernos de países del norte y algunas agencias internacionales. Esta posición está basada en la idea de que los flujos de remesas y la adquisición de nuevas capacidades por los migrantes pueden realmente reforzar el desarrollo de los países del sur. Ante ello, es importante preguntar żQué piensa la gente del sur sobre la migración internacionale ¿Cómo experimentan los migrantes la migración y cómo entienden ellos el desarrollo de sus países de origen? Preguntas que raramente se analizan. Este libro trata de rectificar el balance de la cuestión al propiciar el inicio de un diálogo Sur -Sur y presentar el resultado de las discusiones entre investigadores, funcionarios gubernamentales y líderes de organizaciones de migrantes de los cinco países con mayores flujos migratorios del mundo: India, México, Marruecos, Filipinas y Turquía. Los cinco estudios de caso presentados analizan la experiencia vivida en estos países en los últimos cincuenta años, así como las consecuencias que la migración ha tenido en la economía, la sociedad y la política dentro de ellos. 


\section{Publicaciones}

Después de décadas en las que México era un país que tenía una "política de no tener política" en materia migratoria, la intensidad del fenómeno y la urgencia de sus demandas han provocado que

actores de todos los niveles y ámbitos se involucren con la migración. Entre éstos destacan los

gobiernos de los estados de la República que, ante los espacios que dejó el gobierno federal y las demandas de sus comunidades, terminaron por desarrollar sus propias políticas migratorias con el fin de mitigar los efectos negativos de la migración y, también, de aprovechar su potencial

para el desarrollo de sus respectivas entidades federativas.

Las investigaciones llevaron a la conclusión de que el éxito de la política migratoria de los estados de la federación depende, por un lado, del liderazgo de los gobernadores en el aprovechamiento de

los recursos y políticas federales, y, por otro, de la intensidad de la relación que tengan con sus diásporas en Estados Unidos. No obstante, todos los estados son ya actores importantes en la formulación de la política exterior de México y tienen un efecto significativo en la relación México-Estados Unidos. Sin duda, esto hace evidente la necesidad de pensar en la migración y en la política exterior de México de manera distinta a la tradicional, objetivo del que se originó este volumen, y a continuar analizando lo que nuevos actores están haciendo a este respecto.

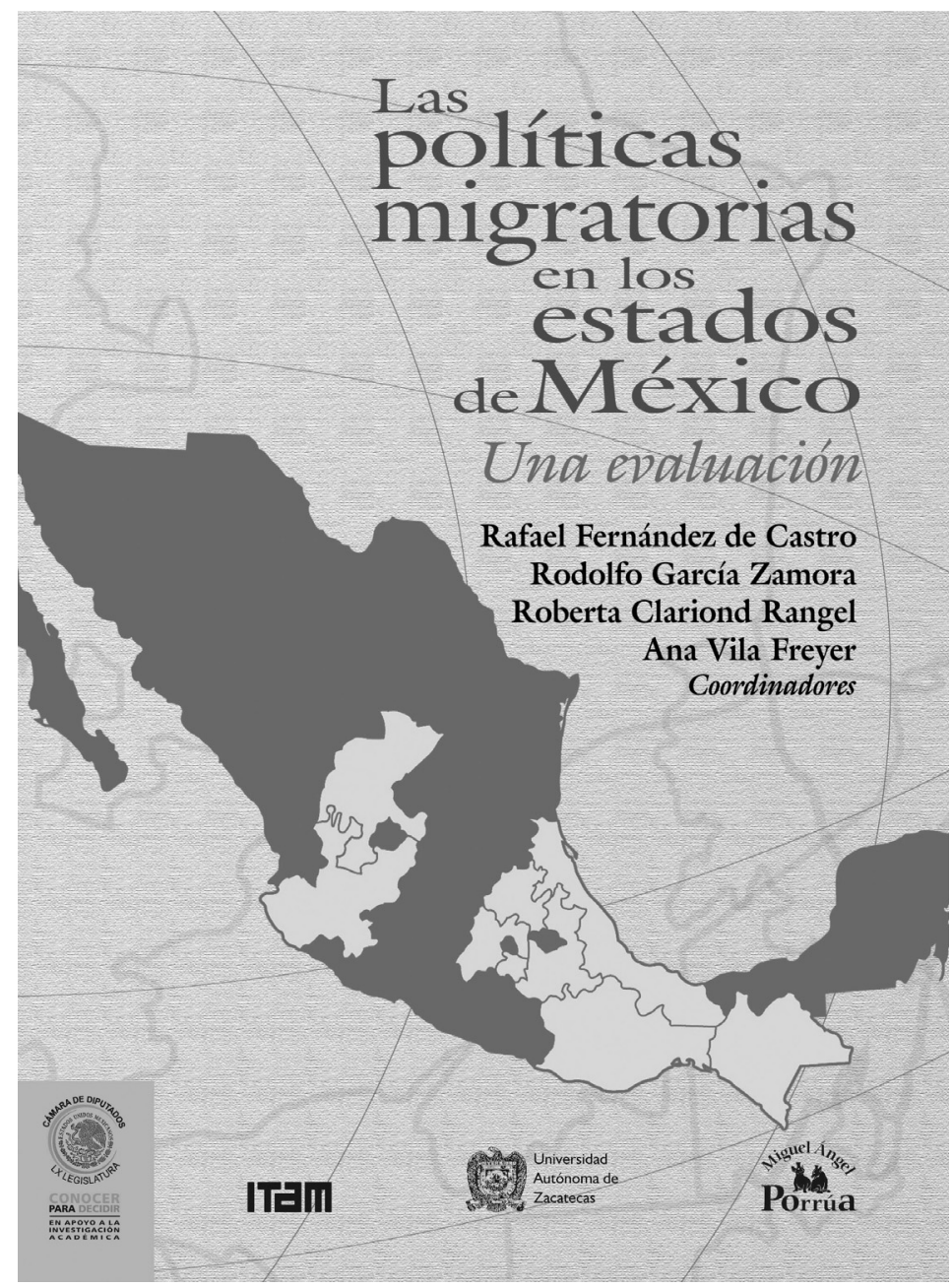




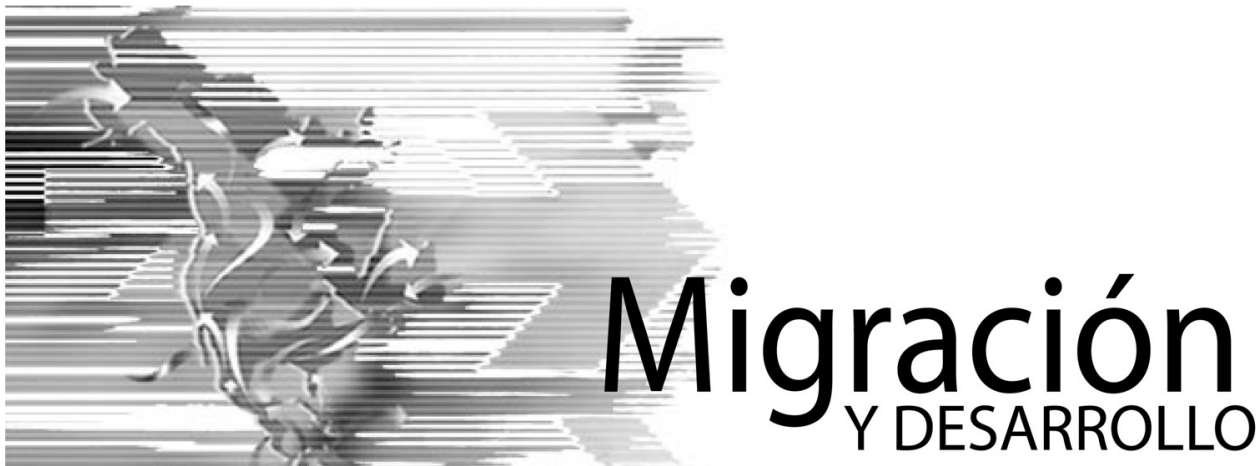

1) Migración y Desarrollo es una revista semestral de investigación científica arbitrada y publicada por la Red Internacional de Migración y Desarrollo.

2) Los trabajos deberán ser inéditos y sus autores se comprometen a no someterlos simultáneamente a la consideración de otras publicaciones. Deberán ser resultado o avance de investigaciones originales de alto nivel, enmarcados en las Ciencias Sociales y enfocados al problema de la migración internacional y el desarrollo. Pueden enviarse trabajos en español, inglés y alemán, y serán publicados en español o inglés. Los autores conceden su permiso para que sus artículos sean difundidos por medios impresos y electrónicos por la Red Internacional de Migración y Desarrollo.

3) Los autores deberán remitir los originales en papel tamaño carta, escrito a doble espacio y por una sola cara, con tamaño de letra de 12 puntos en fuente Times New Roman y perfectamente legible, con alineación justificada, sin enmendaduras ni marcas. Asimismo, se acompañarán del archivo correspondiente en formato compatible con los programas estándares de procesamiento de textos (Word) en plataforma Windows.

4) Considerando que la cuartilla tendrá 27 renglones y entre 60 y 64 caracteres con espacios e interlineado doble, los trabajos tendrán una extensión de entre 20 y 25 cuartillas; los textos canalizados a la sección «La voz de los actores», entre 12 y 15, y a la sección «Coyuntura y debate», entre 15 y 20.

5) Los trabajos deberán contener los siguientes datos: título, nombre completo del autor, nacionalidad, institución, centro de adscripción, cargo que desempeña, número telefónico, dirección postal y dirección electrónica. En caso de coautoría, deberán incluirse los datos de todos los colaboradores.

6) Anexo al artículo, deberá enviarse un resumen de 150 (ciento cincuenta) palabras (o diez renglones) en el idioma en que esté escrito, y cinco palabras clave como máximo que faciliten su inclusión en los índices y bases de datos bibliográficos. Migración y Desarrollo traducirá, en su caso, el resumen al inglés y utilizará esa síntesis para su difusión en el portal de Internet de la propia Red. 


\section{NORMAS PARA LA RECEPCIÓN DE ORIGINALES}

7) Los cuadros, mapas y gráficas deberán presentarse en originales, claros y precisos, e invariablemente deberán incluir la fuente o el origen de procedencia; se agruparán al final del artículo y en el texto deberá indicarse su colocación aproximada.

8) Las notas se presentarán a pie de página y deberán estar escritas a renglón corrido (a un espacio) y numeración corrida (progresiva), e incluirse al pie de la página correspondiente. Las llamadas deberán ser numéricas.

9) Las citas deberán insertase en el texto abriendo un paréntesis con el apellido del autor, el año de la publicación y la página. Ejemplo: (Durand, 2003: 14). Las referencias bibliográficas completas se desplegarán al final del texto.

10) Las referencias bibliográficas deberán ordenarse alfabéticamente al final del texto y sus componentes separados por comas en el orden siguiente: autor o autores (apellidos y nombre), año de edición entre paréntesis, título de la obra en cursivas, volumen o tomo, editorial o institución, número de edición (después de la primera), lugar de edición.

11) Siempre que se emplee una sigla o abreviatura, primero deberá escribirse su equivalencia completa y luego entre paréntesis la sigla o abreviatura que se utilizará con posterioridad.

12) Los trabajos también podrán ser remitidos por correo electrónico de conformidad a las indicaciones anteriores.

13) Los originales serán dictaminados por evaluadores anónimos seleccionados entre expertos del tema tratado por el artículo. En razón de lo cual, los nombres de los autores u otra forma de identificación sólo deberán figurar en la página inicial. Los dictámenes serán comunicados a los autores en un plazo no mayor a 60 días después de la recepción del artículo. El principio de confidencialidad será la guía.

14) Las colaboraciones aceptadas serán sometidas a un proceso de corrección de estilo y su publicación estará sujeta a la disponibilidad de espacio en cada número. En ningún caso se devolverán originales. 
$\mathrm{N} O \mathrm{TAS}$ 